This is the author's final, peer-reviewed manuscript as accepted for publication. The publisher-formatted version may be available through the publisher's web site or your institution's library.

\title{
Process optimization for ethanol production from photoperiod-sensitive sorghum: Focus on cellulose conversion
}

Feng Xu, Karnnalin Theerarattananoon, Xiaorong Wu, Leidy Pena, Yong-Cheng Shi, Scott Staggenborg, Donghai Wang

\section{How to cite this manuscript}

If you make reference to this version of the manuscript, use the following information:

Xu, F., Theerarattananoon, K., Wu, X., Pena, L., Shi, Y.C., Staggenborg, S., \& Wang, D. (2011). Process optimization for ethanol production from photoperiod-sensitive sorghum: Focus on cellulose conversion. Retrieved from http://krex.ksu.edu

\section{Published Version Information}

Citation: Xu, F., Theerarattananoon, K., Wu, X., Pena, L., Shi, Y.C., Staggenborg, S., \& Wang, D. (2011). Process optimization for ethanol production from photoperiodsensitive sorghum: Focus on cellulose conversion. Industrial Crops and Products, 34(1), 1212-1218.

Copyright: Copyright (C) 2011 Elsevier B.V. All rights reserved.

Digital Object Identifier (DOI): doi:10.1016/j.indcrop.2011.04.012

Publisher's Link: http://www.sciencedirect.com/science/article/pii/S0926669011001221

This item was retrieved from the K-State Research Exchange (K-REx), the institutional repository of Kansas State University. K-REx is available at http://krex.ksu.edu 


\section{Process optimization for ethanol production from photoperiod-sensitive sorghum: Focus on cellulose conversion}

Feng $\mathrm{Xu}^{\mathrm{a}}$, Karnnalin Theerarattananoon ${ }^{\mathrm{a}}$, Xiaorong $\mathrm{Wu}^{\mathrm{a}}$, Leidy Pena ${ }^{\mathrm{a}}$, Yong-Cheng Shi ${ }^{\mathrm{b}}$, Scott Staggenborg ${ }^{\mathrm{c}}$, Donghai Wang ${ }^{\mathrm{a},}$

${ }^{a}$ Department of Biological and Agricultural Engineering, Kansas State University, Manhattan, Kansas 66506;

${ }^{\mathrm{b}}$ Department of Grain Science and Industry, Kansas State University, Manhattan, Kansas 66506

${ }^{c}$ Department of Agronomy, Kansas State University, Manhattan, Kansas 66506

* Corresponding author. Tel.: +1 785532 2919; fax: +1 7855325825 .

E-mail address: dwang@ksu.edu (D. Wang). 
Abstract: Photoperiod-sensitive sorghum, as a competitive biomass for ethanol production, was investigated to develop an integrated process for improving ethanol yield. Response surface methodology was employed to study the relationship between pretreatment variables (including temperature, sulfuric acid concentration, and reaction time) and cellulose recovery, as well as efficiency of enzymatic hydrolysis (EEH) in the solid part. Recovery yield decreased and EEH increased as the pretreatment temperature, acidic concentration, and reaction time increased. A model was successfully developed to predict total glucose yield with a maximum value of $82.2 \%$. Conditions of cofermentation were also optimized, and the optimal ethanol yield was obtained with constant-temperature simultaneous saccharification and fermentation at $38^{\circ} \mathrm{C}$. Acetate buffer at a concentration of $50 \mathrm{mM}$ was found helpful for increasing efficiency of enzymatic hydrolysis as well as ethanol yield. The maximum ethanol yield was $0.21 \mathrm{~g}$ ethanol per dry mass at the conditions of $38^{\circ} \mathrm{C}, 0.05 \mathrm{~g}$ yeast/L, and $50 \mathrm{mM}$ acetate buffer. A complete cellulose balance was provided for the whole process.

Keywords: photoperiod-sensitive sorghum; ethanol; response surface methodology; sulfuric acid pretreatment; fermentation.

\section{Introduction}

Production of ethanol from lignocellulosic biomass can effectively reduce the risk of food price increases because of sugar- or starch-based bioethanol production (Fargione et al., 2008; Tilman et al., 2006). Although corn stover has been studied for ethanol production (Zhu et al., 2009), the available amount of corn stover is not sufficient to support biorefineries with an annual production of 36 billion gallons of ethanol in 2022 
(Graham et al., 2007). Photoperiod-sensitive (PS) sorghum, which can grow in semiarid parts of the world and especially in areas too dry for corn, contains a significant amount of soluble sugar and a low ratio of lignin to cellulose. These advantages make PS sorghum an excellent source for bioethanol production.

Many studies about the effects of diluted sulfuric acid pretreatment on enzymatic hydrolysis of cellulose have been reported in which the acid pretreatment was proven effective in removing most of the hemicellulose and some of the lignin component (Schell et al., 2003; Zhu et al., 2004). According to a previous study on PS sorghum (Xu et al., 2011), a harsher condition of pretreatment should be applied to make cellulose easily degradable, thus achieving a high efficiency (more than 90\%) of enzymatic hydrolysis $(\mathrm{EEH})$. Cellulose degradation during high-temperature and diluted sulfuric acid pretreatment comprises the following steps. First, hydrogen bonds between glucan units are broken and cellulose is degraded to cellobiose and glucose; cellobiose is not stable at acid condition and will be degraded to glucose. Glucose will further be degraded to form degradation products (Mosier et al., 2002), some of which are considered inhibitors to yeast fermentation (Klinke et al., 2004). Thus, studying the relationship between cellulose (glucose) recovery and EEH is more important than focusing only on a high EEH, because cellulose loss is not negligible even for mild pretreatment conditions (e.g., $143.2^{\circ} \mathrm{C}, 0.4 \%$ sulfuric acid concentration and $30 \mathrm{~min}$ ) (Bienkowski et al., 1987).

A previous study on diluted sulfuric acid pretreatment of PS sorghum has shown promising results: about $74 \%$ of the sugar source, including cellulose (structural glucose) and soluble sugar (sucrose, glucose, and fructose), could be converted to ethanol (Xu et al., 2011). Thus, an in-depth investigation of how to maximize glucose yield is necessary 
to reveal the relationship between pretreatment conditions and total glucose yield from enzymatic hydrolysis. Response surface methodology (RSM) was employed in this study due to its advantage of efficient design. Because PS sorghum contains a significant amount (about $17.5 \%$ ) of soluble sugar, which can be easily degraded at high temperature and in acid conditions, a direct pretreatment will result in significant sugar loss. An integrated method was designed in this research to solve this problem; this method separates soluble sugar by washing the grounded sample before pretreatment. The washing juice containing soluble sugar was then added to the pretreated sample for cofermentation (Fig. 1).

Although sugar- and starch-based ethanol fermentation has been studied for a long time (Inlow et al., 1988), these processes are different from cellulose-based ethanol fermentation. Simultaneous saccharification and fermentation (SSF) has been accepted in most biomass processing because it saves energy and time and reduces end-product inhibition of enzyme hydrolysis (Wright et al., 1988). The low-biomass loading, which varies depending on material characteristics and pretreatment method, makes it difficult for cellulose-based SSF to achieve a high ethanol concentration (more than $10 \%(\mathrm{v} / \mathrm{v})$ ). Thus, for yeast fermentation of low sugar concentration and low ethanol concentration, substrate inhibition or end-product inhibition is not critical, because it was reported that ethanol begins to inhibit yeast fermentation at $25 \mathrm{~g}$ ethanol/L (Maiorella et al., 1983). Meanwhile, one of the current barriers preventing commercialization of lignocellulosic ethanol is its high processing cost. The optimization of cellulose-based fermentation is consequently supposed to include a mechanism for lowering processing cost. In this 
research, the optimization of SSF was balanced between ethanol yield and processing cost.

The objective of this study was to optimize the processing method, including both pretreatment and co-fermentation (SSF), for maximizing the ethanol yield from PS sorghum.

\section{Materials and Methods}

\subsection{Material preparation and chemicals}

The PS sorghum (1990/AC791) used in this research was harvested from the Kansas State University Agronomy Research Farm in Manhattan, Kansas, from 2007 to 2009. After being ground with a cutting mill (SM 2000, Retsch Inc., Newtown, PA) to less than $1 \mathrm{~mm}$ particle size, the sample with moisture content of $7 \%$ was stored at room temperature. The chemical composition of PS sorghum, analyzed by using the NREL procedure (Sluiter et al., 2004), is $32.5 \%, 19.8 \%, 11.7 \%$ and $17.5 \%$ for cellulose, hemicellulose, lignin, and soluble sugar, respectively. Before sulfuric acid pretreatment, the sample was washed with distilled water to separate soluble sugar and analyzed again for chemical composition. All chemicals used in this research were purchased from Sigma (Sigma-Aldrich, Inc., St. Louis, MO, USA).

\subsection{Sulfuric acid pretreatment}

A reactor (Swagelok, Kansas City Valve \& Fitting Co., KS, USA) made from 316L stainless steel with a measured internal volume of $75 \mathrm{~mL}$ (outside diameter of 38.1 $\mathrm{mm}$, length of $125 \mathrm{~mm}$, and wall thickness of $2.4 \mathrm{~mm}$ ) was used for this study. A 
working volume of $50 \mathrm{~mL}$ was used to allow space for expanding liquid water at high temperature during pretreatment. The loading of the prewashed PS sorghum was $6.1 \%$ (equal to $8.5 \%$ of original dry mass).

A sandbath (Techne, Inc., Princeton, NJ) with a temperature controller was used. After the sand was increased to a certain temperature, the reactor was submerged in boiling sand for different durations according the experimental design presented in Table 1. Then the reactor was immediately transferred to room-temperature water to decrease the internal temperature to below $50{ }^{\circ} \mathrm{C}$ in $2 \mathrm{~min}$. All slurry removed from the reactor was washed, and the solid part was separated by filtration. Part of the solid mass from filtration was used for enzymatic hydrolysis, and the remaining part and the liquid part were used for composition analysis. Cellulose recovery yield $\left(\mathrm{Y}_{\mathrm{REC}}\right)$ was defined as shown in Equation 1.

$$
Y_{R E C}=\frac{M_{p r e t} \times C_{p r e t}}{M_{O R} \times C_{O R}} \times 100 \%
$$

where $\mathrm{M}_{\text {pret }}$ is the dry mass weight after pretreatment, $\mathrm{M}_{\mathrm{OR}}$ is the original dry mass weight, $\mathrm{C}_{\text {pret }}$ is the cellulose percentage of the solid part after pretreatment, and $\mathrm{C}_{\mathrm{OR}}$ is the percentage of cellulose in original dry mass.

\subsection{Enzymatic hydrolysis}

Accellerase $1500^{\circ}$, an enzyme complex including cellulase and $\beta$-glucosidase (Endoglucanase activity: 2200-2900 CMC U/g (one CMC U unit of activity liberates 1 $\mu$ mol of reducing sugars (expressed as glucose equivalents) in 1 min under specific assay conditions of $50{ }^{\circ} \mathrm{C}$ and $\mathrm{pH} 4.8$.), was generously provided by Genencor (Rochester, NY). Accellerase 1500 was used in this study at the recommended dosage $(0.5 \mathrm{~mL}$ per gram 
cellulose). Enzymatic hydrolysis was conducted with the sample after pretreatment at $4 \%$ solids concentration (grams dry weight per $100 \mathrm{~mL}$ ) in $50 \mathrm{mM}$ sodium acetate buffer (pH 5.00) with addition of $40 \mu \mathrm{g} / \mathrm{mL}$ tetracycline and $30 \mu \mathrm{g} / \mathrm{mL}$ cycloheximide. Flasks were incubated in a water bath at $50{ }^{\circ} \mathrm{C}$ and $140 \mathrm{rpm}$. Total monomer sugar analysis was conducted at the end of hydrolysis (72h) on supernatants using high-performance liquid chromatography (HPLC). EEH was defined as shown in the following calculation:

$E E H=\frac{G_{E H} \times 0.9}{M_{E H} \times C_{p r e t}} \times 100 \%$

where $\mathrm{M}_{\mathrm{EH}}$ is the weight of dry mass used in enzymatic hydrolysis (or SSF), $\mathrm{G}_{\mathrm{EH}}$ is the glucose content after hydrolysis, $\mathrm{C}_{\mathrm{pret}}$ is the cellulose percentage of the solid part after pretreatment, and 0.9 is the mass coefficient of glucose to cellulose $(\mathrm{g} / \mathrm{g})$. Total glucose yield $\left(\mathrm{Y}_{\mathrm{p}}\right)$ was defined as the product of cellulose percentage in the solid part after pretreatment and EEH.

$Y_{P}=\frac{E E H \times Y_{R E C}}{100 \%}$

\subsection{Simultaneous saccharification and fermentation}

The same enzyme and buffer system were used in SSF as in enzymatic hydrolysis without antibiotics. Yeast (Ethanol Red, Lesaffre Yeast Corp., Milwaukee, WI) was prepared following the method reported elsewhere (Wu et al., 2010). Both concentrated washing juice and the pretreated solid were added together, and the initial fermentation system contained $4 \%$ (w/v) solids in $50 \mathrm{~mL}$ buffer solution (Fig. 1). The constanttemperature (CT) SSF was conducted in an incubator shaker (Model I2400, New Brunswick Scientific Inc., Edison, NJ) at $38{ }^{\circ} \mathrm{C}$ and $150 \mathrm{rpm}$, whereas the variable- 
temperature (VT) SSF was first conducted in a water bath for $6 \mathrm{~h}$ at $50{ }^{\circ} \mathrm{C}$ and then conducted in an incubator shaker at $30{ }^{\circ} \mathrm{C}$ with inoculation for fermentation. Both CTSSF and VT-SSF were conducted with $50 \mathrm{mM}$ of acetate buffer. An HPLC was used to analyze the ethanol concentration and other end products. Fermentation yield $\left(\mathrm{Y}_{\mathrm{SFF}}\right)$ and total ethanol yield $\left(\mathrm{Y}_{\mathrm{ETH}}\right)$ for the biomass-ethanol production were calculated using the following equations (Equation 4, 5):

$Y_{S S F}=\frac{M_{E P}}{\left(M_{E H} \times C_{p r e t} \times 1.11+M_{H e x}\right) \times 0.511} \times 100 \%$
$Y_{E T H}=\frac{M_{E P}}{M_{T E P}}=\frac{M_{E P}}{\left(M_{O R} \times C_{O R} \times 1.11+M_{H e x}\right) \times 0.511} \times 100 \%$

where $\mathrm{M}_{\mathrm{EP}}$ is mass of ethanol after SSF, $\mathrm{M}_{\mathrm{TEP}}$ is the theoretical value calculated from cellulose and soluble sugar, $\mathrm{M}_{\mathrm{Hex}}$ is the total amount of soluble sugar (expressed as glucose equivalents), 0.511 is the mass coefficient of glucose to ethanol $(\mathrm{g} / \mathrm{g}), \mathrm{M}_{\mathrm{OR}}$ is the original dry mass weight, $\mathrm{C}_{\mathrm{OR}}$ is percentage of the cellulose in original dry mass, and 1.11 is the mass coefficient of cellulose to glucose $(\mathrm{g} / \mathrm{g})$.

\subsection{Sugar and ethanol analysis}

Monosaccharide and ethanol concentration were analyzed by using an HPLC with a Rezex RPM-monosaccharide column (300*7.8 mm; Phenomenex, CA) and a Refractive Index Detector (RID -10A, Shimadzu, MD). The column was eluted with double-distilled water at a flow rate of $0.6 \mathrm{~mL} / \mathrm{min}$. The temperature of the chromatograph column was maintained at $80^{\circ} \mathrm{C}$.

\subsection{Response surface methodology}


Box-Behnken design was employed to optimize the processing conditions of pretreatment and hydrolysis. Three coded levels were used for those conditions: concentration of sulfuric acid, pretreatment time, and temperature. The behavior of the system was explained by the following equation:

$Y=\beta_{0}+\sum \beta_{i} x_{i}+\sum \beta_{i j} x_{i} x_{j}+\sum \beta_{i j} x_{i}^{2}[6]$

where $\beta \beta$ represents the coefficient for each term and $\mathrm{x}$ represents condition parameter.

According to the results of previous experiments, the optimal condition for acquiring the highest total glucose yield $\left(\mathrm{Y}_{\mathrm{p}}\right)$ could be in the range of 140 to $160{ }^{\circ} \mathrm{C}, 30$ to $50 \mathrm{~min}$, and 0.5 to $1.5 \%$ for temperature, time, and acid concentration, respectively. Table 1 shows the experiment design and corresponding results of EEH, $\mathrm{Y}_{\mathrm{REC}}$, and $\mathrm{Y}_{\mathrm{p}}$. Fifteen trials were performed in random order.

\subsection{Statistics and software}

Data were analyzed by using analysis of variance (ANOVA) and Tukey's studentized range (HSD) test in SAS (SAS Institute, Inc. Cary, NC, USA). RSM results were analyzed with Design Expert (Stat-Ease, Inc. Minneapolis, MN, USA). Mean values from the duplicated experiments were reported.

\section{Results and discussion}

\subsection{Optimization of pretreatment and hydrolysis by RSM}

Through analysis and optimization in Design Expert, three different models were obtained corresponding to the three response values. ANOVA was then conducted to remove insignificant terms. Finally, the three reduced models for EEH, $Y_{R E C}$, and $Y_{p}$ 
were obtained as shown (Equations 7, 8, and 9). The ANOVA for EEH showed that the model is highly significant $(P<0.0001)$, and the value of R-squared was 0.9877 , indicating the regression model could provide good prediction. Lack-of-fit test was used to measure the failure of the model by representing data in the experimental domain at the points that are not included in the regression (Rastogi and Rashmi, 1999). In this study, the test implied that lack-of-fit was insignificant, which suggested the model fit the experimental data. The reduced model (Equation 7) for EEH suggested that the EEH increased as the variables (temperature, time, and concentration) increased. During sulfuric acid pretreatment, the main structure was supposed to be disrupted (Zeng, 2007), and most of the amorphous parts (hemicellulose and lignin) of PS sorghum were degraded or dissolved under certain conditions (Xu et al., 2011). This could result in an increase of surface area of cellulose that was considered as an important parameter during enzyme hydrolysis (Fan et al., 1980). Many studies also have reported that EEH increased with surface area (Paakkari and Serimaa, 1984; Puri and Pearce, 1986), which could explain why EEH increased with those variables. The 3-D response surface image (Fig. 2) suggested that the interaction between temperature and concentration was significant and the EEH would increase up to $100 \%$, although the mass loss and/or cellulose loss would be significant (Table 1). The equation is:

$$
\begin{aligned}
& E E H=-1064.5+12.47 \times A+0.2951 \times B+103.3 \times C \\
& -0.3908 \times A \times C-0.03435 \times A^{2}-14.73 \times C^{2}
\end{aligned}
$$

where $\mathrm{A}$ represents temperature, $\mathrm{B}$ represents time, and $\mathrm{C}$ represents acidic concentration.

Although the glucose in the acid solution after pretreatment can be recovered by neutralization, the further degradation of glucose under harsher conditions would not only increase glucose (cellulose) loss, but also generate a significant amount of degradation 
products (such as hydroxymethylfurfural), some of which are considered inhibitors of yeast fermentation (Liu et al., 2004). Therefore, recovering either glucose or water may cost too much in industry. For this consideration, it is important to limit cellulose loss and glucose degradation. Another reduced model was then obtained to study the cellulose recovery yield ( $\mathrm{Y}_{\mathrm{REC}}$ ) (Equation 8). The ANOVA showed the model is highly significant in terms of lack-of-fit and has high R-squared value (0.9849), indicating the regression model represents the real relationship among those variableswell. The interaction between time and concentration was insignificant, whereas the interactions between temperature and time and between temperature and concentration were significant. From this model, $\mathrm{Y}_{\mathrm{REC}}$ was found to decrease as those variables increased, which is entirely different from the case of EEH. This could be explained by understanding structural change during acid pretreatment. With pretreatment under mild conditions, the lignocellulosic structure was slightly disrupted and amorphous parts were partially removed; cellulose degradation to glucose is not significant because cellulose is embedded in the cell wall. With a strong pretreatment condition, the outside structure was seriously damaged, and cellulose loss or degradation increased with the increasing variables. Furthermore, as a result of cellulose degradation, glucose is amenable, especially in low-pH, high-temperature conditions (Xiang et al., 2004), resulting in the decrease of cellulose recovery (including solid liquid parts) during pretreatment.

$$
\begin{aligned}
& Y_{R E C}=-1041.8+13.65 \times A+3.693 \times B+129.8 \times C \\
& -0.02506 \times A \times B-0.888 \times A \times C-0.04014 \times A^{2}
\end{aligned}
$$

For yeast-ethanol fermentation, obtaining as high sugar (glucose) yield as possible

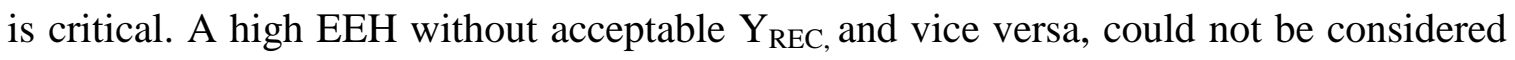
for application. Thus, the model for total glucose yield $\left(\mathrm{Y}_{\mathrm{p}}\right)$ was generated to predict the 
best yield after pretreatment and hydrolysis. Because the experimental data for $Y_{p}$ are calculated by multiplying EEH and $\mathrm{Y}_{\mathrm{REC}}$, a quadratic model may not fit the data well. A cubic model was then considered. ANOVA was conducted again to generate a reduced model (Equation 9). The interaction between temperature and time and the interaction between temperature and concentration were also significant based on lack-of-fit and high value of R-squared (0.9975) (Fig. 3). According to the cubic model, the highest glucose yield was expected to be $82.07 \%$ at the optimal condition of $157.7^{\circ} \mathrm{C}, 41.6 \mathrm{~min}$ and $1.27 \%$ acid concentration. Further experiments at this condition were conducted and the expected value was obtained (82.2\%), which means that RSM was used successfully in processing optimization.

$Y_{p}=-193.26-1424.9 \times C+0.06042 \times A \times B+19.58 \times A \times C+7.855 \times 10^{-3} \times A^{2}$ $-0.02683 \times B^{2}-17.14 \times C^{2}-2.930 \times 10^{-4} \times A^{2} \times B-0.06494 \times A^{2} \times C$

In addition, for maximizing utilization of those available resources (including glucose and water) optimization of glucose yield is suggested to include both the solid and liquid parts after pretreatment (Equation 10). Undegraded glucose in solution was supposed to be added to SSF system for ethanol production. Then a neutralization of the filtrate after pretreatment could be suggested. However, the neutralized filtrate contains different compounds which could have complicated effects on yeast fermentation. The coefficient (k) that takes into account the negative effect was introduced, but it is not easy to obtain because of complicated interactions in SSF system. If the molecules degraded from glucose are assumed to have negative effects on yeast fermentation, the maxima of $Y_{p}$ ' and $Y_{p}$ will be obtained at the same certain pretreatment condition in which glucose degradation is not significant (less than $0.5 \%$ of total glucan/cellulose, as found in the liquid with optimized pretreatment). In this case, the coefficient $\mathrm{k}$ tends to be equal to 1 ; 
then $Y_{p}$ could be used in this optimization for simplifying the calculation. In addition, depending on the substrate used in the fermentation process, xylose also could be considered for optimization with this method, although it is not the focus of the present study.

$Y_{p}^{\prime}=k\left(Y_{p}+Y_{G}\right)$

where $Y_{G}$ represents the glucose amount degraded from cellulose in liquid after pretreatment, $\mathrm{Y}_{\mathrm{p}}$ ' represents the total glucose amount that could be efficiently converted to ethanol by yeast, and the coefficient $\mathrm{k}$ represents the negative effects (inhibitors) to yeast-ethanol fermentation.

\subsection{Effect of temperature and inoculation on SSF}

Ethanol yields were previously compared by performing a separated fermentation in which the washing juice and solids were used for fermentation (or SSF) separately, and a co-fermentation in which the washing juice and solids were mixed together. The results showed no significant difference in the total ethanol yield between the separated fermentation and co-fermentation (data not shown). Then different inoculation amounts and SSF temperatures were investigated (Fig. 4). In CT-SSF at $38^{\circ} \mathrm{C}$, initial ethanol production was found at $2 \mathrm{~h}$, and the initial conversion rate in the first $6 \mathrm{~h}$ increased as the inoculation amount increased. The highest ethanol yield $(894 \mathrm{mg})$ was found with an inoculum of $0.05 \mathrm{~g}$ (dry yeast cells)/L (Fig. 4a). Although a longer lag phase was found with this inoculation, more than $95 \%$ of final ethanol yield was obtained in $27 \mathrm{~h}$, indicating that the small amount of inoculum $(0.05 \mathrm{~g} / \mathrm{L})$ is sufficient for fermentation of current substrate loading at a low cost. The ethanol yields with inoculation amounts of 
$0.1 \mathrm{~g} / \mathrm{L}$ and $0.2 \mathrm{~g} / \mathrm{L}$ were relatively lower than yield with the inoculation amount of 0.05 g/L, which was also found in VT-SSF (Fig. 4b). The reason could be that the initial sugar concentration was relatively low (about $15 \mathrm{~g} / \mathrm{L}$ ) compared with high-loading starch-based fermentation. No soluble sugar was detected after $24 \mathrm{~h}$, indicating the consumption rate of glucose was higher than the hydrolysis rate. In this case, the larger yeast inoculum could be consuming more sugar initially for non-fermentative pathways. Future study of variation in viable yeast cells during SSF is suggested to understand kinetics of cell growth. Because no significant difference occurred in ethanol yield after $48 \mathrm{~h}$ with 0.05 $\mathrm{g} / \mathrm{L}$ inoculation, the SSF could be finished in less than two days, thus reducing processing cost.

For VT-SSF, the effect of inoculation amount on ethanol fermentation was similar to that of CT-SSF. The optimal temperature for yeast-ethanol fermentation was reported to be $30{ }^{\circ} \mathrm{C}$ (Lin and Tanaka, 2006). In this study, however, the final ethanol yield of VTSSF, in which ethanol fermentation was conducted at $30^{\circ} \mathrm{C}$, was lower than that of CT$\operatorname{SSF}\left(38^{\circ} \mathrm{C}\right)$ with the same inoculum. Considering the fact that the enzymatic hydrolysis could not finish in the first $6 \mathrm{~h}$ at $50{ }^{\circ} \mathrm{C}$, we suggest that the reason for low ethanol yield could be the low activity of many cellulases at $30{ }^{\circ} \mathrm{C}$ during the subsequent hydrolysis. Composition test of the residues after SSF was conducted to verify the hypothesis. The results showed that the cellulose amount in the residue after VT-SSF was $5.8 \%$ higher than that in the residue of CT-SSF, indicating that the EEH of VT-SSF was lower than that of CT-SSF, which ultimately resulted in the lower ethanol yield.

\subsection{Effect of buffer (acetic acid) on SSF}


Acetic acid has been reported to inhibit yeast fermentation because acetate is considered soluble in the lipids of yeast cell membranes, which results in membrane disruption and affects the membrane transport of phosphate (Conway and Downey, 1950). However, by comparing the ethanol yield of SSF with different buffer concentrations, we found that the ethanol yield of $900 \mathrm{mg}$ occurred at $100 \mathrm{mM}$ buffer concentration (about $34 \mathrm{mM}$ acetic acid), and the lowest ethanol yield occurred with no buffer (Fig. 5). The increase in ethanol yield could be explained by the increase in requirement of adenosine triphosphate (ATP) (Maiorella et al., 1983). When acetic acid exists at a low concentration, the negative effect of membrane disruption on yeast cells is not significant; yeast cells are supposed to pump the protons out of the cells to neutralize intracellular $\mathrm{pH}$, and the ATP needed to accomplish this procedure could be obtained from ethanol formation in an anaerobic environment. When a higher concentration of acetic acid (200 $\mathrm{mM}$ buffer, equal to $68 \mathrm{mM}$ acetic acid) is applied, however, the membranes of yeast cells are much more disrupted and membrane transport of phosphate is significantly affected, which ultimately results in a decreased ethanol yield. For the SSF without buffer, the final $\mathrm{pH}$ was found to be 3.55 , which is significantly lower than the $\mathrm{pH}$ range (4.8 to 5.0) needed to maintain enzyme (cellulase) activity. Thus, the EEH may decrease with low enzyme activity. This could be one of the reasons for decreased ethanol yield. To verify this assumption, we conducted a composition test after fermentation. The undigested cellulose after SSF without buffer was 30.3\% more than that after SSF with $50 \mathrm{mM}$ buffer, which confirmed that the buffer system is helpful in improving ethanol yield. Because no significant difference occurred in the ethanol yield between $50 \mathrm{mM}$ and $100 \mathrm{mM}$, we suggested using $50 \mathrm{mM}$ to reduce cost. 


\subsection{Cellulose balance}

A detailed cellulose (glucose) balance, as well as mass balance, for the whole conversion process at the optimal conditions is shown in Fig. 1. About $88.7 \%$ of cellulose could be recovered in the solid part for the following SSF after the optimal pretreatment process. Under the conditions of $38{ }^{\circ} \mathrm{C}, 50 \mathrm{mM}$ acetate buffer, and $0.05 \mathrm{~g} / \mathrm{L}$ yeast inoculation, $77.2 \%$ of the total sugar source (including cellulose and soluble sugar) could be converted to ethanol with SSF. The total ethanol yield was $894 \mathrm{mg}$ after $72 \mathrm{~h}$ of cofermentation from $4.23 \mathrm{~g}$ PS sorghum (about $0.21 \mathrm{~g}$ ethanol per gram dry mass).

\section{Conclusion}

The sulfuric acid pretreatment and enzymatic hydrolysis of PS sorghum were optimized together using RSM, and three models were obtained successfully for analysis. The maximum glucose yield from the solid part is $82.2 \%$. Cellulose recovery from the solid part decreased and EEH increased as the pretreatment temperature, resident time, and acidic concentration increased. The optimization on SSF suggested that the conditions of $0.05 \mathrm{~g} / \mathrm{L}$ inoculation and $38{ }^{\circ} \mathrm{C}$ CT-SSF were effective for ethanol production $(894 \mathrm{mg} / 50 \mathrm{~mL}, 2.3 \%(\mathrm{~V} / \mathrm{V}))$. Acetate acid was found to affect ethanol fermentation, and the optimal buffer concentration is $50 \mathrm{mM}$. Under optimal process conditions, $77.2 \%$ of total sugar source could be converted to ethanol, which is equal to a final yield of $0.21 \mathrm{~g}$ ethanol/g dry mass. Further study of obtaining concentrated ethanol in final broth is suggested to reduce recovery cost. 


\section{Acknowledgements}

The authors were grateful for cellulase from Genencor (A Danisco division, Rochester, NY). Contribution number 11-037-J from the Kansas Agricultural Experiment Station.

\section{LITERATURE CITED}

Bienkowski, P., Ladisch, M., Narayan, R., Tsao, G., Eckert, R. 1987. Correlation of Glucose (Dextrose) Degradation at 90 to $190 \mathrm{C}$ in 0.4 to $20 \%$ Acid. Chem. Eng. Commun. 51(1), 179-192.

Conway, E., Downey, M. 1950. An outer metabolic region of the yeast cell. Biochem. J. 47(3), 347.

Fan, L., Lee, Y., Beardmore, D. 1980. Mechanism of the enzymatic hydrolysis of cellulose: effects of major structural features of cellulose on enzymatic hydrolysis. Biotechnol. Bioeng. 22(1), 177-199.

Fargione, J., Hill, J., Tilman, D., Polasky, S., Hawthorne, P. 2008. Land clearing and the biofuel carbon debt. Science 319(5867), 1235.

Graham, R., Nelson, R., Sheehan, J., Perlack, R., Wright, L. 2007. Current and potential US corn stover supplies. Agron. J. 99(1), 1.

Inlow, D., McRae, J., Ben-Bassat, A. 1988. Fermentation of corn starch to ethanol with genetically engineered yeast. Biotechnol. Bioeng. 32(2), 227-234.

Klinke, H., Thomsen, A., Ahring, B. 2004. Inhibition of ethanol-producing yeast and bacteria by degradation products produced during pre-treatment of biomass. Appl. Microbiol. Biotechnol. 66(1), 10-26.

Lin, Y., Tanaka, S. 2006. Ethanol fermentation from biomass resources: current state and prospects. Appl. Microbiol. Biotechnol. 69(6), 627-642.

Liu, Z., Slininger, P., Dien, B., Berhow, M., Kurtzman, C., Gorsich, S. 2004. Adaptive response of yeasts to furfural and 5-hydroxymethylfurfural and new chemical evidence for HMF conversion to 2, 5-bis-hydroxymethylfuran. J. Ind. Microbiol. Biotechnol. 31(8), 345-352.

Maiorella, B., Blanch, H.W., Wilke, C.R. 1983. By-product inhibition effects on ethanolic fermentation by $\langle\mathrm{I}\rangle$ Saccharomyces cerevisiae $</ \mathrm{I}\rangle$. Biotechnol. Bioeng. 25(1), 103-121.

Mosier, N., Ladisch, C., Ladisch, M. 2002. Characterization of acid catalytic domains for cellulose hydrolysis and glucose degradation. Biotechnol. Bioeng. 79(6), 610-618.

Paakkari, T., Serimaa, R. 1984. A study of the structure of wood cells by X-ray diffraction. Wood Science and Technology 18(2), 79-85.

Puri, V.P., Pearce, G.R. 1986. Alkali-explosion pretreatment of straw and bagasse for enzymic hydrolysis. Biotechnol. Bioeng. 28(4), 480-485.

Rastogi, N., Rashmi, K. 1999. Optimisation of enzymatic liquefaction of mango pulp by response surface methodology. Eur. Food Res. Technol. 209(1), 57-62.

Schell, D., Farmer, J., Newman, M., McMillan, J. 2003. Dilute-sulfuric acid pretreatment of corn stover in pilot-scale reactor. Appl. Biochem. Biotechnol. 105(1), 69-85. 
Sluiter, A., Hames, B., Ruiz, R., Scarlata, C., Sluiter, J., Templeton, D., Crocker, D. 2004. Determination of structural carbohydrates and lignin in biomass. NREL, Golden, $C O$.

Tilman, D., Hill, J., Lehman, C. 2006. Carbon-negative biofuels from low-input highdiversity grassland biomass. Science 314(5805), 1598.

Wright, J., Wyman, C., Grohmann, K. 1988. Simultaneous saccharification and fermentation of lignocellulose. Appl. Biochem. Biotechnol. 18(1), 75-90.

Wu, X., Staggenborg, S., Propheter, J., Rooney, W., Yu, J., Wang, D. 2010. Features of sweet sorghum juice and their performance in ethanol fermentation. Industrial crops and products 31(1), 164-170.

Xiang, Q., Lee, Y., Torget, R. 2004. Kinetics of glucose decomposition during dilute-acid hydrolysis of lignocellulosic biomass. Appl. Biochem. Biotechnol. 115(1), 11271138.

Xu, F., Shi, Y.-C., Wu, X., Theerarattananoon, K., Staggenborg, S., Wang, D. 2011. Sulfuric acid pretreatment and enzymatic hydrolysis of photoperiod sensitive sorghum for ethanol production. Bioprocess and Biosystems Engineering, In Press.

Zeng, M. 2007. Microscopic examination of changes of plant cell structure in corn stover due to hot water pretreatment and enzymatic hydrolysis. Biotechnol. Bioeng. 97(2), 265.

Zhu, Y., Lee, Y., Elander, R. 2004. Dilute-acid pretreatment of corn stover using a highsolids percolation reactor. Appl. Biochem. Biotechnol. 117(2), 103-114.

Zhu, Z., Sathitsuksanoh, N., Vinzant, T., Schell, D., McMillan, J., Zhang, Y. 2009. Comparative study of corn stover pretreated by dilute acid and cellulose solventbased lignocellulose fractionation: Enzymatic hydrolysis, supramolecular structure, and substrate accessibility. Biotechnol. Bioeng. 103(4), 715-724. 
Table 1 Experimental design with response surface methodology

\begin{tabular}{ccccccc}
\hline Trials & Temperature & Time & Concentration & EEH $(\%)^{\mathrm{a}}$ & $\mathrm{Y}_{\mathrm{REC}}(\%)^{\mathrm{b}}$ & $\mathrm{Y}_{\mathrm{p}}(\%)^{\mathrm{c}}$ \\
\hline 1 & 180 & 40 & 0.5 & 94.32 & 67.77 & 63.92 \\
2 & 160 & 50 & 1.5 & 92.17 & 84.91 & 78.25 \\
3 & 160 & 40 & 1 & 90.47 & 89.54 & 81.01 \\
4 & 180 & 30 & 1 & 94.2 & 61.82 & 58.24 \\
5 & 180 & 50 & 1 & 98.86 & 42.62 & 42.14 \\
6 & 160 & 40 & 1 & 91.57 & 89.86 & 82.28 \\
7 & 160 & 50 & 0.5 & 89.84 & 88.66 & 79.65 \\
8 & 160 & 30 & 1.5 & 92.12 & 84.84 & 78.16 \\
9 & 140 & 40 & 0.5 & 42.66 & 94.84 & 40.46 \\
10 & 140 & 50 & 1 & 57.71 & 94.94 & 54.79 \\
11 & 180 & 40 & 1.5 & 94.88 & 32.8 & 31.13 \\
12 & 140 & 40 & 1.5 & 58.85 & 95.39 & 56.13 \\
13 & 160 & 40 & 1 & 88.98 & 90.11 & 80.17 \\
14 & 160 & 30 & 0.5 & 72.76 & 95.71 & 69.63 \\
15 & 140 & 30 & 1 & 48.89 & 94.09 & 46 \\
\hline
\end{tabular}

${ }^{a}$ EEH: Efficiency of enzymatic hydrolysis.

${ }^{\mathrm{b}} \mathrm{Y}_{\mathrm{REC}}$ : Cellulose recovery yield during pretreatment at the solid part.

${ }^{c} Y_{\mathrm{p}}$ : Total glucose yield during both pretreatment and hydrolysis. 


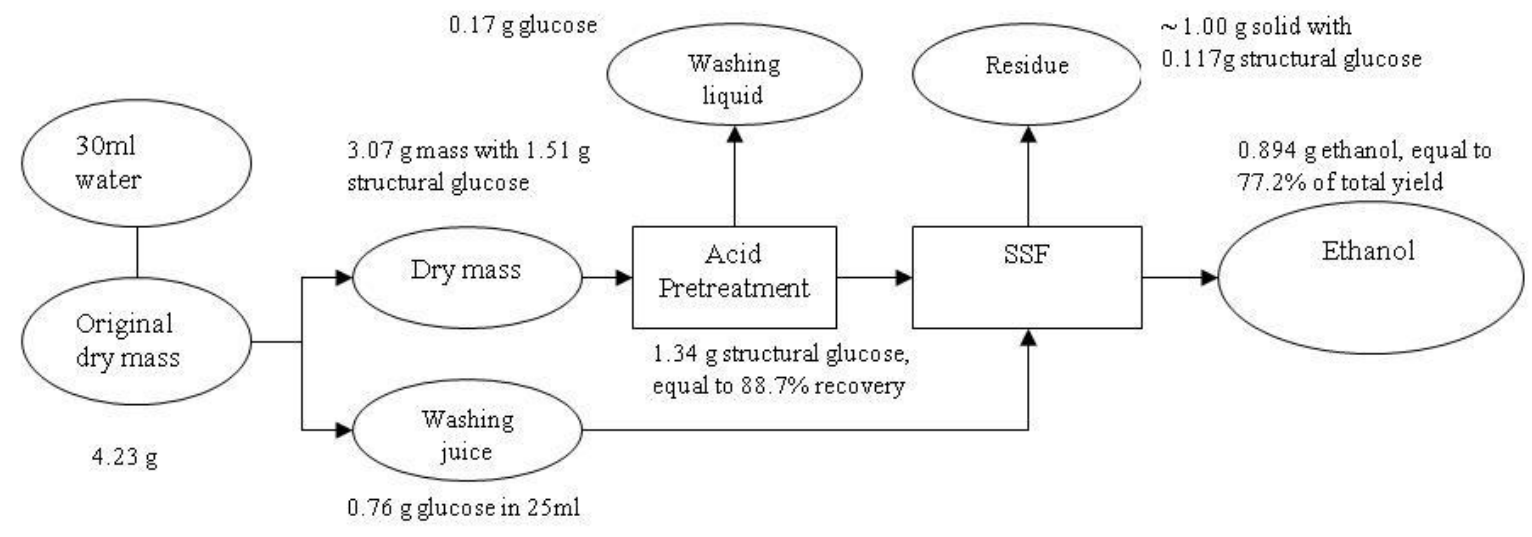

Figure 1. Cellulose balance of pretreatment and simultaneous saccharification and fermentation for ethanol production 


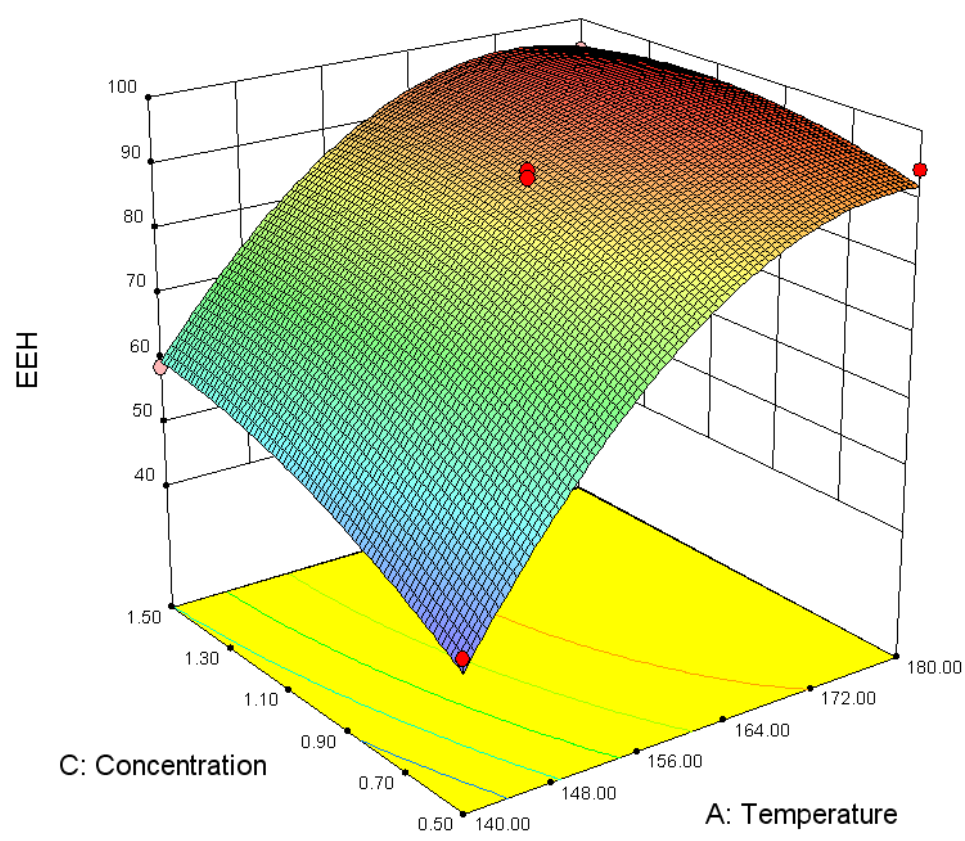

Figure 2. 3-D response surface of EEH in relation to temperature and concentration 

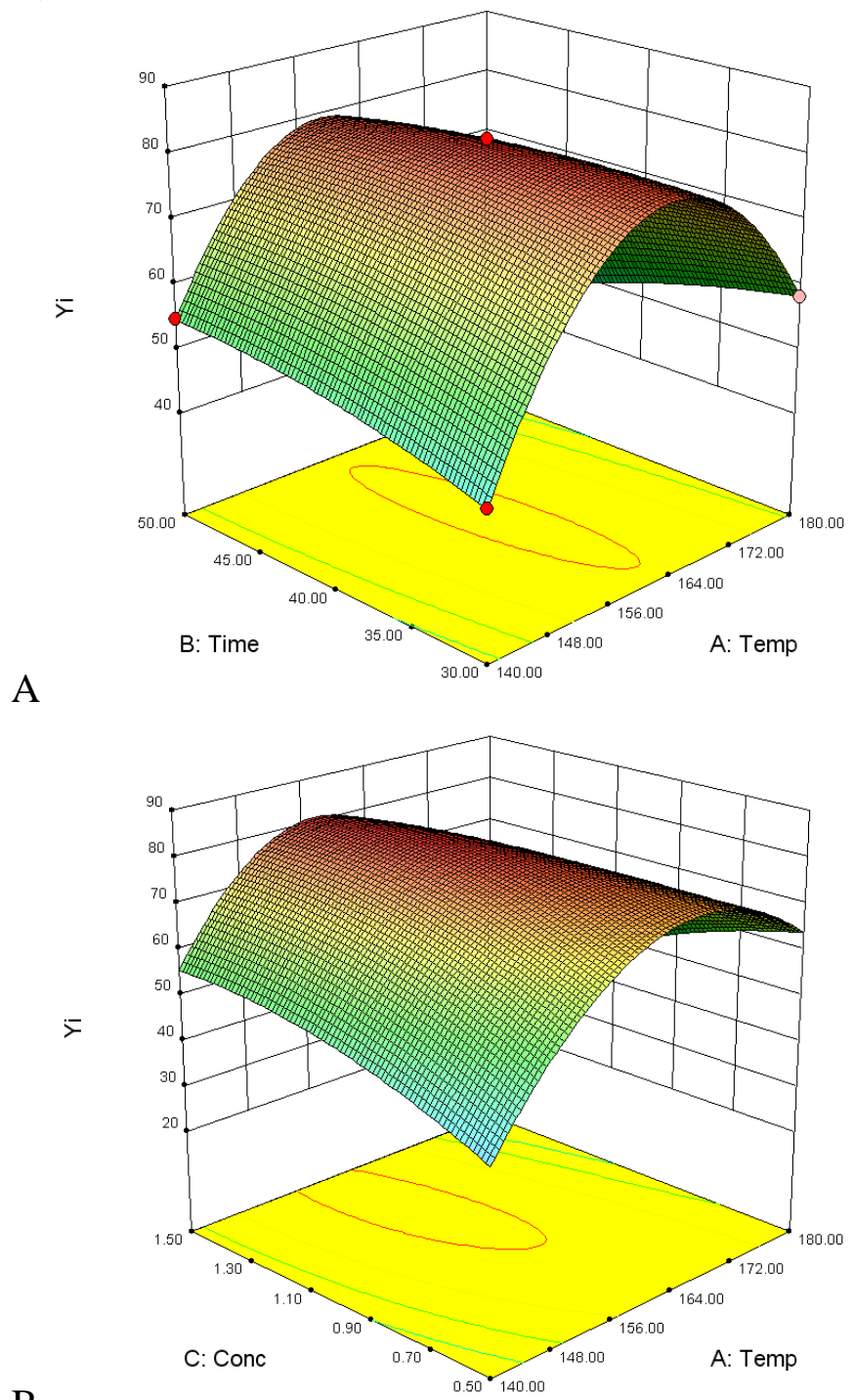

B

Figure 3. 3-D response surface of total glucose yield in relation to (A) temperature and time, and (B) temperature and concentration. 

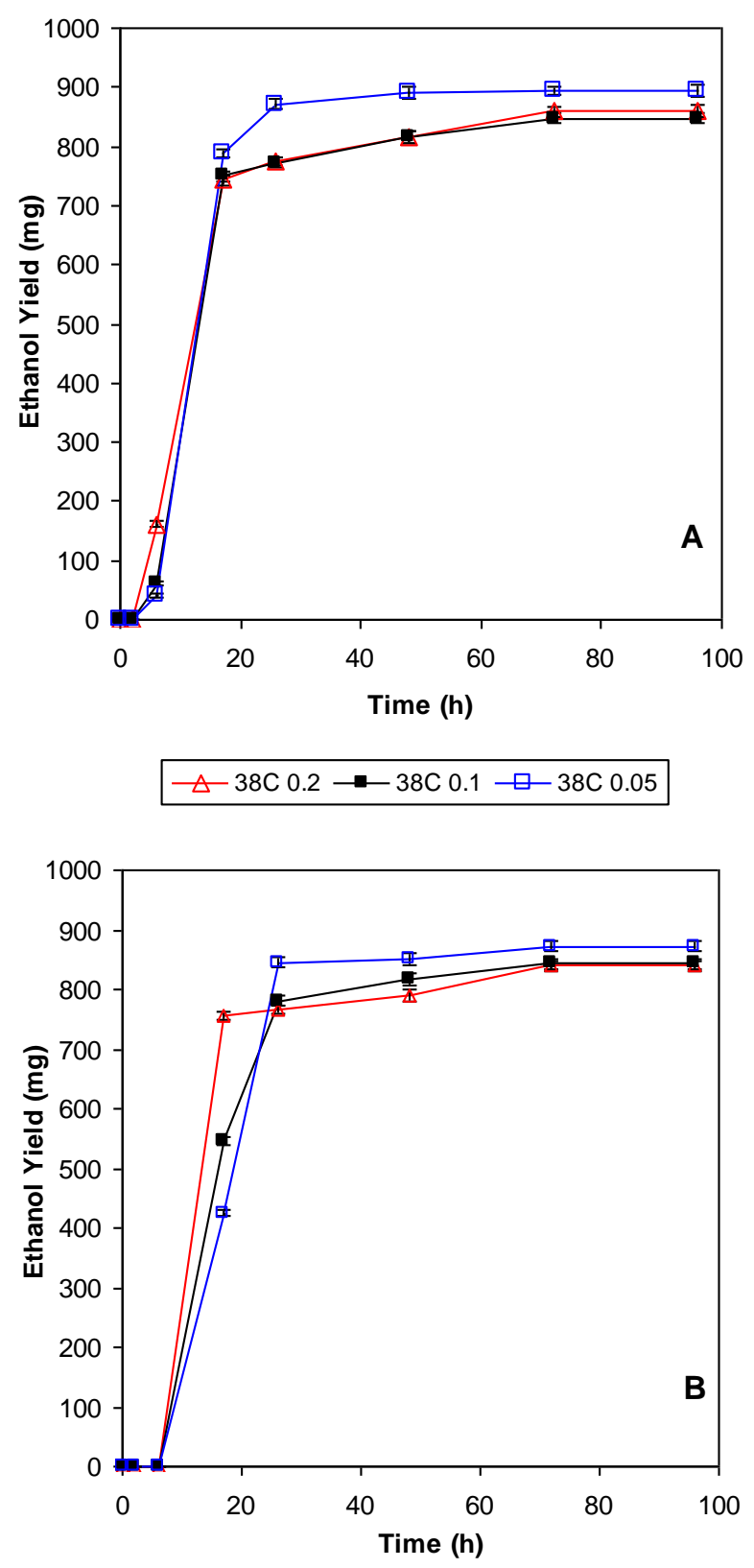

$\triangle 50-30 \mathrm{C} 0.2 \rightarrow-50-30 \mathrm{C} 0.1 \rightarrow 50-30 \mathrm{C} 0.05$

Figure 4. Effect of inoculation on constant-temperature $\left(38^{\circ} \mathrm{C}\right)$ simultaneous saccharification and fermentation (SSF) (A), and variable-temperature SSF $\left(50^{\circ} \mathrm{C}\right.$ for $6 \mathrm{~h}$ enzymatic hydrolysis and $30^{\circ} \mathrm{C}$ for SSF) (B). 


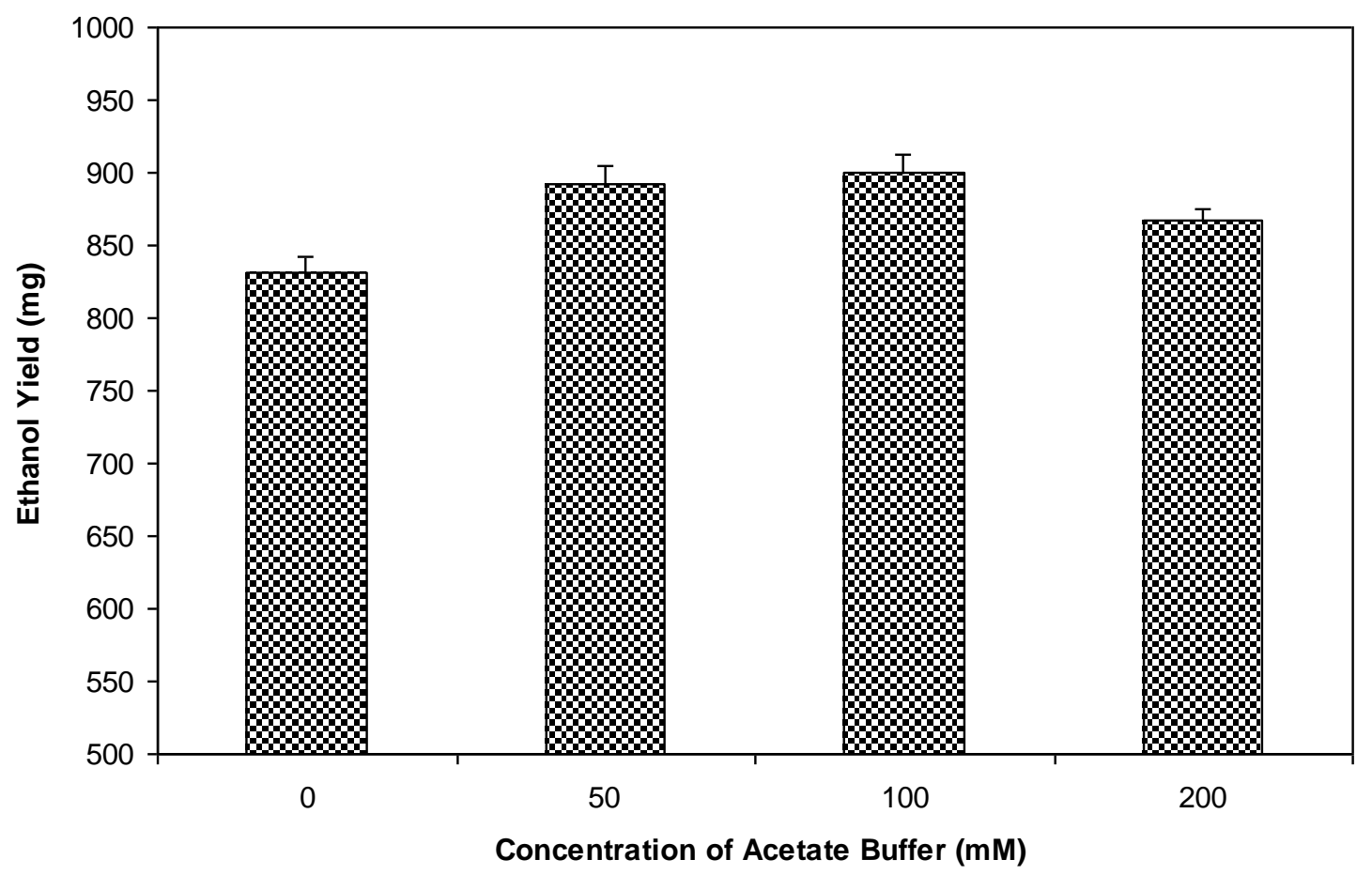

Figure 5. Effect of acetate buffer concentration on ethanol yield 